\title{
Feasibility of percutaneous transluminal angioplasty for carotid artery stenosis
}

\author{
Martin M Brown, Paul Butler, Jeremy Gibbs, Michael Swash, John Waterston
}

\begin{abstract}
Percutaneous transluminal balloon angioplasty was attempted in seven patients with internal carotid artery stenosis, including one patient who had two procedures. All had recurrent, carotid territory, neurological symptoms considered haemodynamic in origin. Six had occlusion of the contralateral internal carotid artery. Cerebral blood flow studies confirmed diminished cerebrovascular reserve in six patients studied. In five patients (six procedures) angioplasty of the stenosed internal carotid artery was carried out successfully. With two patients technical difficulty in crossing the stenosis prevented angioplasty and in one patient with bilateral stenosis the procedure was not attempted on the second side because of the severity of the stenosis. In two patients transient aphasia developed during cannulation of the carotid artery and in another a transient monoparesis developed during the procedure. Both these haemodynamic complications recovered within ten minutes. No other complications occurred. Our experience suggests that balloon angioplasty is technically feasible in the management of stenotic carotid disease associated with haemodynamic stroke. It is a technically simple procedure requiring only a brief admission to hospital. However, its general application to patients with thromboembolic carotid-territory stroke will depend on the risk/benefit ratio compared to carotid endarterectomy or to conventional medical treatment.
\end{abstract}

Departments of

Neurology and Neuroradiology, The London Hospital, Whitechapel, London M M Brown P Butler

J Gubbs

M Swash

J Waterston

Correspondence to: Dr M Swash, The London Hospital, Whitechapel, London E1 1BB, United Kingdom.

Received 3 May 1989

and in revised form

14 August 1989.

Accepted 21 November 1989 stenosis or contralateral internal carotid artery occlusion, the aim may be to improve cerebral perfusion pressure. However, carotid endarterectomy carries significant risks. The reported risk of death or permanent stroke following carotid endarterectomy varies from $21 \%$ to $2 \%$ in different series. ${ }^{34}$

The average combined mortality and stroke risk between different centres has been estimated at around $6 \% .^{5}$ The major risk is of stroke in the territory of the operated artery but there is also significant morbidity from stroke in vascular territories not directly related to the operated artery and from myocardial infarction, particularly in patients with ischaemic heart disease or severe hypertension. ${ }^{6}$ There are also local risks, such as cranial nerve palsy and anaesthetic risks, such as pulmonary embolism. ${ }^{4}$ Because of these problems we have investigated the feasibility of percutaneous transluminal angioplasty (PTA) in the management of selected patients with symptomatic stenosis of the internal carotid artery. This procedure is brief, and does not require a surgical incision, or general anaesthesia. Since the development of appropriate balloon dilation catheters, ${ }^{7-9}$ PTA has become established in the treatment of peripheral, renal and coronary vascular disease. Its success rates in these situations approaches $90 \%$, complications occurring in less than $5 \%$ of procedures. ${ }^{1011}$

In contrast, angioplasty of vessels supplying the intracranial circulation has not been recommended because of anxiety about the risks of cerebral embolism following the procedure. ${ }^{1112}$ However, web-like stenosis of the common carotid artery has been successfully dilated with a catheter passed retrogradely through an arteriotomy, performed for endarterectomy at the carotid bifurcation, ${ }^{13}$ and by PTA. ${ }^{14}$ Fibromuscular dysplasia of the internal carotid artery ${ }^{1415}$ and of brachial vessels, including the subclavian, vertebral and external carotid arteries ${ }^{16-18}$ has also been successfully treated with PTA. With increasing experience of PTA at these and other sites, a few reports of PTA performed successfully for atherosclerotic stenosis of the internal carotid artery have appeared suggesting that PTA might be used in place of carotid endarterectomy in selected cases, in contrast to earlier opinion. ${ }^{19-22}$ In this report we describe our initial experience of PTA in haemodynamic stroke due to internal carotid artery stenosis.

\section{Subjects and methods}

Patients were offered internal carotid PTA as an alternative to carotid endarterectomy if they 


\begin{tabular}{|c|c|c|c|c|c|c|c|c|}
\hline \multirow[b]{2}{*}{ Patient } & \multirow[b]{2}{*}{ Presentation } & \multirow[b]{2}{*}{ CT changes } & \multirow{2}{*}{$\begin{array}{l}\text { Internal carotid } \\
\text { angiography }\end{array}$} & \multicolumn{2}{|c|}{$\begin{array}{l}\text { Cerebrovascular } \\
\text { reserve }^{\star}\end{array}$} & \multirow{2}{*}{$\begin{array}{l}\text { Angioplasty } \\
\text { procedure }\end{array}$} & \multirow[b]{2}{*}{ Complications } & \multirow[b]{2}{*}{ Follow up } \\
\hline & & & & $L$ & $R$ & & & \\
\hline 1 & $\begin{array}{l}\text { Minor stroke-left } \\
\text { face and arm } \\
\text { weakness TIA's- } \\
\text { visual blurring }\end{array}$ & $\begin{array}{l}\text { Bi-parietal } \\
\text { cortical } \\
\text { infarction }\end{array}$ & $\begin{array}{l}\text { Occlusion } L \\
\text { Severe stenosis R }\end{array}$ & $2 \cdot 1$ & $2 \cdot 7$ & $\begin{array}{l}R \text { internal carotid- } \\
\text { successful }\end{array}$ & Nil & $\begin{array}{l}\text { Symptom free at } 18 \\
\text { months }\end{array}$ \\
\hline 2 & $\begin{array}{l}\text { TIA's-dysphasia. } R \\
\text { hand weakness }\end{array}$ & $\mathbf{N}$ & $\begin{array}{l}\text { Occlusion L? } \\
\text { dissection } \\
\text { Severe stenosis } R \\
\text { (fibromuscular } \\
\text { dysplasia) }\end{array}$ & -0.6 & $0 \cdot 3$ & $\begin{array}{l}\mathbf{R} \text { internal carotid- } \\
\text { unsuccessful }\end{array}$ & $\begin{array}{l}\text { Transient aphasia } \\
\text { during attempted } \\
\text { passage of guide wire }\end{array}$ & $\begin{array}{l}\text { Symptom free on } \\
\text { anti-coagulants at } 12 \\
\text { months }\end{array}$ \\
\hline 3 & $\begin{array}{l}\text { TIA's-dysarthia, } L \\
\text { sided weakness and } \\
\text { sensory loss }\end{array}$ & $R$ frontal lacune & $\begin{array}{l}\text { Occlusion } \mathrm{L} \\
\text { Severe stenosis R }\end{array}$ & 1.9 & $2 \cdot 3$ & $\begin{array}{l}\text { R internal carotid- } \\
\text { unsuccessful }\end{array}$ & Nil & $\begin{array}{l}R \text { carotid } \\
\text { endarterectomy } \\
\text { Continues to have } \\
\text { episodic retinal } \\
\text { ischaemia }\end{array}$ \\
\hline 4 & $\begin{array}{l}\text { TIA's-drop } \\
\text { attacks, mild left } \\
\text { hemiparesis }\end{array}$ & $\begin{array}{l}\text { Bilateral lacunar } \\
\text { infarction }\end{array}$ & $\begin{array}{l}\text { Occlusion R } \\
\text { Severe stenosis } \mathrm{L}\end{array}$ & 1.4 & -0.1 & $\begin{array}{l}\text { L internal carotid- } \\
\text { successful }\end{array}$ & Nil & $\begin{array}{l}\text { Symptom free at } 6 \\
\text { months }\end{array}$ \\
\hline \multirow[t]{2}{*}{5} & $\begin{array}{l}\text { TIA's—bilateral face } \\
\text { and arm sensory }\end{array}$ & $\mathrm{N}$ & $\begin{array}{l}\text { Occlusion L } \\
\text { Moderate stenosis } \\
\mathbf{R}\end{array}$ & $2 \cdot 0$ & 2.5 & $\begin{array}{l}R \text { internal carotid- } \\
\text { successful }\end{array}$ & $\begin{array}{l}\text { Transient } L \text { hand } \\
\text { weakness during } \\
\text { inflation }\end{array}$ & \multirow[t]{2}{*}{$\begin{array}{l}\text { One TIA during } 6 \\
\text { months, then further } \\
\text { TIA's before 2nd } \\
\text { procedure }\end{array}$} \\
\hline & $\begin{array}{l}\text { Recurrent TIA's-L } \\
\text { arm weakness, } 9 \\
\text { months post } \\
\text { angioplasty }\end{array}$ & & Similar findings & & & $\begin{array}{l}\text { Repeat } R \text { internal } \\
\text { carotid }\end{array}$ & Nil & \\
\hline 6 & $\begin{array}{l}\text { Minor stroke- } \\
\text { dysphasia and R arm } \\
\text { weakness }\end{array}$ & $\begin{array}{l}\text { Small } L \text { frontal } \\
\text { cortical and } \\
\text { lacunar infarcts }\end{array}$ & $\begin{array}{l}\text { Occlusion L Mild } \\
\text { stenosis R }\end{array}$ & 0.9 & 0.7 & $\begin{array}{l}R \text { internal carotid- } \\
\text { successful }\end{array}$ & Nil & $\begin{array}{l}\text { Symptom free at } 4 \\
\text { months }\end{array}$ \\
\hline 7 & $\begin{array}{l}\text { TIA's-L sided } \\
\text { weakness and } L \\
\text { amaurosis fugax }\end{array}$ & $\mathbf{N}$ & $\begin{array}{l}\text { Bilateral severe } \\
\text { stenoses }\end{array}$ & NP & & $\begin{array}{l}\mathrm{L} \text { internal carotid- } \\
\text { successful } \\
\mathrm{R} \text { internal carotid } \\
\text { too stenosed for } \\
\text { angioplasty }\end{array}$ & $\begin{array}{l}\text { Transient aphasia } \\
\text { and } R \text { arm weakness } \\
\text { during inflation. } \\
\text { False aneurysm } L \\
\text { side on repeat } \\
\text { angiography }\end{array}$ & $\begin{array}{l}\text { R carotid } \\
\text { endarterectomy } \\
\text { Symptom free at } 4 \\
\text { months }\end{array}$ \\
\hline
\end{tabular}

${ }^{\star}$ Increase in cerebral blood flow after carbon dioxide inhalation for each hemisphere expressed as \% increase in cerebral blood flow/mmHg rise in pC02 (normal mean: $3.4_{0}^{\circ}$ )

Severe stenoses $>75 \%$ reduction in luminal diameter

Moderate stenosis $>50^{\circ}$ oreduction in luminal diameter

Mild stenosis $>30^{\circ}$ or reduction in luminal diameter

$\mathrm{N}=$ Normal

$\mathrm{NP}=$ Not performed

had a history of recent appropriate cerebrovascular events and if initial investigations showed smooth stenotic lesions of the internal carotid artery without evident ulceration or thrombosis. Patients were only considered for PTA if they were felt to be at high risk of recurrent stroke and if they would otherwise have been offered open carotid endarterectomy. Patients with angiographic or clinical features which increased the risk of carotid endarterectomy were also included.

The seven patients (table 1) who fulfilled these criteria gave fully informed consent to the procedure as required by the Ethical Committee of The London Hospital. Their ages ranged from 46-64 years (mean 55 years). Four were female and three male. Four had significant atherosclerotic stenosis at the origin of one internal carotid artery associated with complete occlusion of the contralateral internal carotid artery (cases 1, 3, 4 and 5). One had severe internal carotid artery stenosis associated with only minor stenosis of the contralateral internal carotid artery (case 6). Another patient had an irregular, short, $95 \%$ segmental stenosis of the upper cervical internal carotid artery secondary to fibromuscular dysplasia, associated with complete occlusion of the contralateral internal carotid artery due to dissection (case 2), whilst the seventh patient had bilateral severe stenoses of the internal carotid arteries. Two patients presented with minor strokes (cases 1 and 6) and five presented with recurrent transient ischaemic attacks (TIAs). In the latter,
TIAs had continued despite aspirin or anticoagulant therapy. Three patients gave a history consistent with a haemodynamic origin for their symptoms in that TIAs occurred in association with assumption of the erect posture, or during a hot shower. One patient, with recurrent TIAs despite anticoagulant therapy, that occurred nine months after a technically successful angioplasty, had repeat angioplasty on the same artery (case 5).

In six patients there was diminished cerebrovascular reserve in the symptomatic hemisphere as determined by a significantly reduced cerebral blood flow response to hypercapnia (table), measured by the non-invasive Xenon $^{133}$ technique. $^{23}$ Five patients had medical conditions which were felt to increase the risks of surgery. Two of these had severe ischaemic heart disease, one had poorly controlled hypertension, one had rheumatoid arthritis and one had such severe ankylosing spondylitis of her cervical spine that endarterectomy was impossible. In one patient with fibromuscular dysplasia the site of the stenosis was surgically inaccessible.

\section{Protocol}

All the procedures were undertaken by one of us (PB). Before angioplasty, each patient was fully anticoagulated with warfarin for between two and four weeks. The procedure was performed under sedation with droperidol $5 \mathrm{mg}$ iv, and fentanyl $0.1 \mathrm{mg}$ iv. The anticholinergic action of droperidol was valuable in countering 
any reflex bradycardia resulting from manipulation of the carotid bifurcation. Heart rate, blood pressure and the electrocardiogram were monitored throughout the procedure.

A "Check-Flo" 7.5 French gauge introducer sheath (Wm Cook, Europe A/S) was inserted via the right femoral artery. Preformed 5 French gauge "Headhunter" (HNI) or "Sidewinder" (Simmons II) balloon dilation catheters were used (Wm Cook, Europe A/S). Each balloon was $1.5 \mathrm{~cm}$ long and could be inflated to a diameter of $5 \mathrm{~mm}$ at a maximum extended for $1 \mathrm{~cm}$ beyond the balloon. Catheter placement was assisted by a $0.028^{\prime \prime}$ diameter Teflon-coated straight guidewire with a $5 \mathrm{~cm}$ floppy tip. Just before balloon inflation, arterial blood was withdrawn into a heparinised $50 \mathrm{ml}$ syringe from the sidearm of the introducer sheath. Whilst the balloon was inflated this blood was injected at a rate of approximately $100 \mathrm{ml} / \mathrm{min}$ through the catheter lumen to maintain some perfusion of the hemisphere rostral to the temporarily occluded internal carotid artery.

Up to three dilations, each of 40 seconds

Fig Carotid arterial digital subtraction angiograms (lateral projections) of two patients $(a)$ before and (b) after balloon dilation of internal carotid artery stenoses (arrowheads). pressure of 3 atmospheres. The catheter tip

duration and at least two minutes apart, were performed using an "Indeflator Plus" (Advanced Cardiovascular Systems Inc) to monitor the exact inflation pressure. During angioplasty each patient was asked to report the development of any symptoms to a neurologist in attendance. In addition, the neurologist conducted a limited neurological examination (speech, facial and extremity movement and plantar responses) at frequent intervals. Any change in the neurological examination was an indication for immediate withdrawal of the catheter.

\section{Results}

Internal carotid PTA was carried out successfully in five of the seven patients (table). In three of these the procedure was carried out entirely without complications. Two patients developed transient contralateral symptoms during balloon inflation which resolved fully after ten minutes. One of these patients had a repeat angioplasty performed on the same artery nine months later without complication There was no undue haemorrhage at the
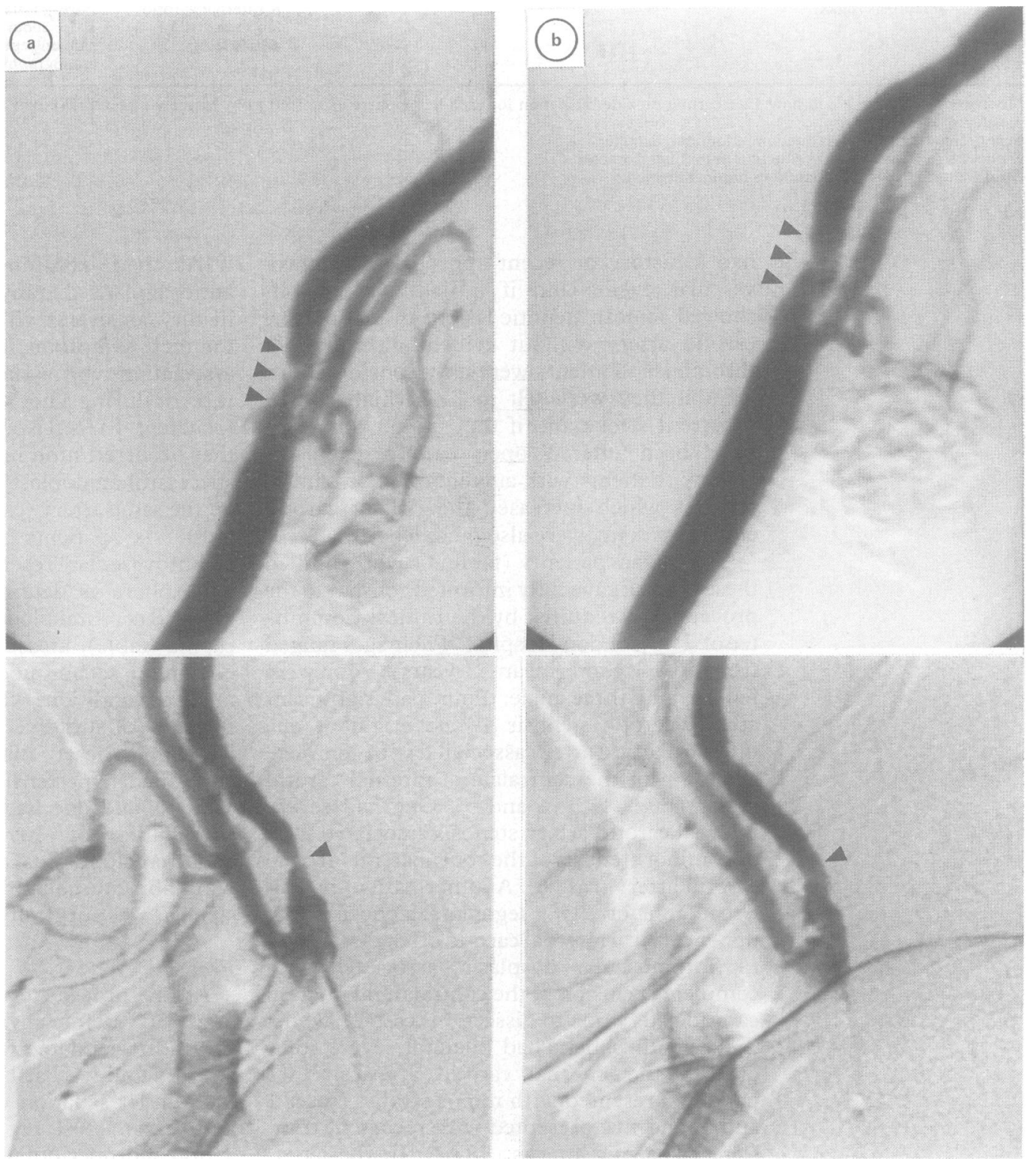
arterial puncture site. Angiography immediately following the procedure showed an increase in the luminal diameter in these five patients (fig). Intravenous digital subtraction angiography at six weeks showed that this improvement had persisted in two patients but in another two there was no appreciable change from the appearances before angioplasty (the fifth patient has not yet been restudied). In no case was the internal carotid artery stenosis worse. One patient had a small false aneurysm noted at the site of the previous angioplasty on repeat angiography which has not been clinically symptomatic. Following PTA one patient has had recurrent TIAs and has recently had a repeat angioplasty performed; the other four patients have remained well with no further neurological episodes during follow up periods ranging from four to 18 months.

In two patients (cases 2 and 3) angioplasty was not successful. In case 3 it proved technically impossible to cannulate the internal carotid artery because of an anatomical variant. In case 2 , in whom internal carotid stenosis was secondary to fibromuscular dysplasia, it proved impossible to cross the stenotic lesion with a guide wire. During attempted passage of the guide wire, the patient developed transient aphasia lasting five minutes and the procedure was abandoned. There was no permanent neurological deficit. In an additional case not listed, selective internal carotid angiography immediately before cannulation showed a large atheromatous ulcer, unsuspected from the intravenous digital subtraction study. Since this finding was an exclusion criterion in our protocol for PTA the procedure was not attempted. This patient, in addition to cases 3 and 7 was later successfully treated by conventional carotid endarterectomy.

\section{Discussion}

Our experience shows that percutaneous angioplasty (PTA) of the internal carotid arteries is a feasible alternative to endarterectomy and can be successfully carried out without major complications in suitable patients. PTA has major advantages over endarterectomy in terms of resource allocation and patient comfort, and in avoiding general anaesthesia. The procedure itself is technically simple and there is immediate ascertainment of any neurological complications since the patient remains conscious throughout. No specialised nursing care is required and the patient can be discharged 24 hours after angioplasty.

Our seven patients were carefully selected. All had recurrent TIAs or strokes with continued symptoms despite medication with aspirin or anticoagulants. They were considered to be at high risk for further stroke. Three had a history which strongly suggested a haemodynamic origin for their symptoms. Six had tight internal carotid artery stenosis associated with occlusion of the contralateral internal carotid artery and the six who had blood flow studies had evidence of impaired cerebrovascular reserve suggesting a haemodynamic origin for their symptoms. Improvement in perfusion pressure by dilating the internal carotid artery was therefore likely to be beneficial. All had relatively smooth stenotic lesions of the internal carotid artery of a type for which we would usually recommend endarterectomy. Six had at least one feature thought to increase the risk of carotid endarterectomy, for example, contralateral carotid occlusion, ischaemic heart disease or severe hypertension. ${ }^{6}$ In one patient the stenosis was surgically inaccessible. Repeat PTA was performed on the same artery in one patient without complication.

The risks of internal carotid PTA are as yet undefined. Our series of seven patients extends the total published case reports to 23 in which internal carotid artery PTA has been attemped. ${ }^{19-22}$ Two of our patients developed transient neurological symptoms during balloon inflation lasting less than 10 minutes. One other instance has been reported in which a patient developed a transient ischaemic attack 20 minutes after the procedure ${ }^{20}$ but no major complications have been reported. The most serious theoretical risk of PTA is cerebral embolism due to dislodgement of thrombus or of atheromatous material from the vessel wall. We therefore avoided patients with angiographic features of atheromatous ulceration or thrombus in the carotid artery and regarded impaired cerebrovascular reserve as a more appropriate indication for PTA than potential amelioration of thrombogenic pathology. To reduce the risk of embolisation further, our patients were anticoagulated with warfarin for two weeks before angioplasty. Theron et al ${ }^{22}$ used temporary distal balloon occlusion of the internal carotid artery in five patients to prevent embolisation during PTA of more proximal atherosclerotic lesions. However, in our patients with haemodynamic insufficiency the duration of total occlusion of the internal carotid artery required by that technique (up to 10 minutes) would have considerably increased the risk of the procedure.

Laboratory and necropsy studies of angioplasty for atherosclerotic lesions suggest two main pathophysiological mechanisms responsible for the increase in vessel diameter. ${ }^{24-27}$ If, when distended, the balloon diameter is slightly greater than that of the stenotic section, stretching of the vessel wall occurs with superficial desquamation of intimal elements. Superficial splits may occur in atherosclerotic plaque. Healing of the intima with endothelialisation results in a larger lumen. If the balloon diameter when distended is much greater than that of the stenosis, then deep focal splits occur in the intima and plaque leaving the relatively elastic media intact. Over the subsequent few weeks the intima then retracts and the elastic media, freed from the encasing effects of the intima, distends. In some cases splits may extend through the media, as in one of our patients who developed an asymptomatic false aneurysm, but arterial rupture has not been described. The splits may lead to the angiographic appearance of intimal dissection, but this is limited to the area of the angioplasty and only rarely leads to delayed secondary occlusion. Compression or redistribution of 
atheromatous material does not appear to play an important part in the response to angioplasty. Embolism of damaged intima or plaque material appears to be uncommon in peripheral PTA $^{1128}$ but splits in the intima or plaque provide obvious sites for thrombus formation and subsequent post-angioplasty thrombotic occlusion or embolisation. In our protocol, therefore, anticoagulation was continued for four to six weeks after PTA. Others have used aspirin, ${ }^{22}$ dipyridamole ${ }^{21}$ or a short course of heparin ${ }^{20}$ following carotid PTA.

We were particularly concerned that haemodynamic cerebral ischaemia might occur in our patients during temporary occlusion of the internal carotid artery by the inflated balloon. We therefore limited the period of balloon inflation to 40 seconds and waited at least 120 seconds before repeating it. In order to minimise the fall in perfusion pressure oxygenated arterial blood was injected through the lumen of the catheter during balloon inflation. The maximum flow rate that could be achieved was about $100 \mathrm{mls}$ per minute. Despite this, two patients developed transient neurological symptoms during inflation of the balloon. Haemodynamic cerebral ischaemia is unlikely to lead to infarction so long as inflation of the balloon is of limited duration $(<1$ minute), and controlled by neurological observation. These symptoms were felt to be additional evidence for haemodynamic compromise in the patients that were affected.

Selective carotid angiography itself carries a small risk. The component of this risk related to contrast medium dosage was limited in our studies by the digital subtraction technique which limits the dose of contrast medium required for angiography. The use of an introducer sheath minimises trauma to the femoral artery if a catheter needs to be exchanged for another of a different configuration during the procedure. Because of the lack of torque of the small calibre catheters used, technical difficulties were encountered in several cases. Modifications to the catheterguidewire systems may improve selective internal carotid cannulation. The success rate of carotid PTA is likely to improve with increasing experience.

Inflation of the balloon did not stimulate the carotid sinus since there was no associated change in pulse or blood pressure. This may reflect the site of the stenoses, which were all distal to the carotid bifurcations. Reflex bradycardia and hypertension may be a problem in patients with common carotid or bifurcation stenosis. ${ }^{22}$ Appropriate premedication should be used in such cases. It has been suggested that stretching the carotid artery may induce reflex local arterial spasm $^{18}$ but we did not encounter this complication. A local infusion of papaverine or general anaesthesia may relieve this spasm. ${ }^{1821}$

A major advantage of carotid PTA over endarterectomy is that the procedure is carried out in an alert and cooperative patient. Apart from avoiding the risks of general anaesthesia this allows continuous monitoring of the patient's neurological state, with immediate deflation of the balloon and withdrawal of the catheter in the event of complications. Evoked potential monitoring could also be used but we have preferred to use clinical examination because it is sensitive to changes within the middle cerebral artery territory and is directly relevant to the clinical problem.

The role of PTA in the treatment of carotid stenosis is as yet undefined. We suggest that PTA of the internal carotid artery is most suitable for patients with smooth lesions in whom haemodynamic mechanisms may be responsible for ischaemic cerebral symptoms. This is particularly likely in patients with continuing symptoms following carotid occlusion. ${ }^{23}$ The failure of the international extracranial/intracranial arterial bypass study to show any benefit of bypass surgery even in patients with carotid occlusion ${ }^{29}$ has redirected interest towards endarterectomy of contralateral stenotic lesions as a means of improving perfusion pressure in both hemispheres. Our experience shows that PTA provides a feasible alternative. PTA is also suitable for treatment of surgically inaccessible high lesions of the internal carotid artery, such as fibromuscular dyplasia and for the treatment of symptomatic restenosis of the carotid artery following endarterectomy, where surgical re-exploration is hazardous. ${ }^{22} 3031$ It may also be indicated for restenosis following angioplasty. Many strokes in patients with cerebrovascular disease result from thrombo-embolism, but the potential role of PTA in this situation is less clear than in haemodynamic stroke. The analogy with angioplasty for coronary artery disease, however, suggests that PTA may be appropriate. $^{32}$ Larger, long term studies are needed to define the appropriate indications, risks and outcome of PTA for carotid stenosis. Whether, and in which circumstances, the final balance will favour angioplasty will depend on its risk/benefit ratio compared to carotid endarterectomy and to conventional medical treatment.

We are grateful to the manufacturers of the catheters (William Cook, Europe A/S) who have been instantly responsive to our requirements. Sister J Baker and the staff of the Radiology Department of The London Hospital provided invaluable assistance during the angioplasty procedures. The measurements of cerebrovascular reserve were carried out at The National Hospital, Queen Square.

1 North American Symptomatic Carotid Endarterectomy Group. Carotid endarterectomy: three critical evaluations. Stroke 1987;18:987-9.

2 Winslow CM, Solomon DH, Chassin MR, Kosecoff J Merrick NJ, Brook RH. The appropriateness of carotid endarterectomy. New Engl J Med 1988;318:721-7.

3 Easton JD, Sherman DG. Stroke and mortality rate in carotid endarterectomy: 228 consecutive operations. Stroke 1977;8:565-8.

4 Browse NL, Ross-Russell RW. Carotid endarterectomy and the Javid Shunt: the early results of 215 consecutive operations for transient ischaemic attacks. B J Surg 1984; 71:53-7.

5 Dyken ML. Carotid endarterectomy studies: A glimmering of science. Stroke 1986;17:355-8.

6 Sundt TM, Sandok BA, Whisnant JP. Carotid endarterectomy: complications and pre-operative assessment of risk. 
Mayo Clin Proc 1975;50:301-6.

7 Dotter CT, Judkins MP. Transluminal treatment of arteriosclerotic obstruction: Description of a new technique and preliminary report of its application. Circulation nique and prelimina

8 Gruntzig A, Kumpe DA. Technique of percutaneous transluminal angioplasty with a Gruntzig balloon catheter. American Journal of Roentgenology 1979;132:547-52.

9 Abele JB. Balloon catheters and transluminal dilatationtechnical considerations. American Journal of Roentgenology 1980;135:901-6.

10 Campbell WB. Angioplasty for intermittent claudication. $\mathrm{Br}$ Med J 1986;293:1047-8.

11 Health and Public Policy Committee, American College of Physicians. Percutaneous transluminal angioplasty. Annals of Internal Medicine 1983;99:864-9.

12 Fallon JT. Pathology of arterial lesions amenable to percutaneous transluminal angioplasty. American Journal of Roentgenology 1980;135:913-6.

13 Kerber CW, Cromwell LD, Loehden OL. Catheter dilatation of proximal carotid stenosis during distal bifurcation
endarterectomy. American Journal of Neuroradiology endarterectom

14 Mullan S, Duda EE, Partonas NJ. Some examples of balloon technology in Neurosurgery. J Neurosurg 1980;52:321-9.

15 Hasso AN, Bird CR, Zinke DE, Thompson JR. Fibromucular dysplasia of the internal carotid artery: Percutaneous transluminal angioplasty. American Journal of Neuroradiology 1981;2:175-80.

16 Motarjeme A, Keifer JW, Zuska AJ. Percutaneous transluminal angioplasty of the vertebral arteries. Radiology 1981;139:715-7.

17 Motarjeme A, Keifer JW, Zuska AJ. Percutaneous transluminal angioplasty of the brachiocephalic arteries. American Journal of Neuroradiology 1982;3:169-74.

18 Vitek JJ. Percutaneous transluminal angioplasty of the external carotid artery. American Journal of Neuroexternal carotid artery.

19 Wiggli U, Gratzl O. Transluminal angioplasty of stenotic carotid arteries-case reports and protocol. American Journal of Neuroradiology 1983;4:793-5.

20 Bockenheimer SAM, Mathias K. Percutaneous transluminal angioplasty in arteriosclerotic internal carotid artery stenosis. American Journal of Neuroradiology 1983;4:791-2.

21 Tsai FY, Matovich V, Hiesheima G, et al. Percutaneous transluminal angioplasty of the carotid artery. American Journal of Neuroradiology 1986;7:349-58.

22 Theron J, Raymond J, Casasco A, Courthoux F. Percutaneous angioplasty of atherosclerotic and post-surgical stenosis of the carotid arteries. American Journal of Neuroradiology 1987;8:495-500.

23 Brown MM, Wade JPH, Bishop CCR, Ross-Russell RW. Reactivity of the cerebral circulation in patients with carotid occlusion. J Neurol Neurosurg Psychiatry 1986;
49:899-904.

24 Castaneda-Zuniga WR, Formanek A, Tadavarthy $M$, et al. The mechanism of balloon angioplasty. Radiology 1980;135:565-71.

25 Block PC, Fallon JT, Elmer D. Experimental angioplastylessons from the laboratory. American Journal of Roentgenology 1980;135:907-12.

26 Block P, Myler RK, Stertzer S, Fallon JT. Morphology after transluminal angioplasty in human beings. New Engl J Med 1981;305:382-5.

27 Clouse ME, Tomashefski JF, Reinhold RE, Costello P. The mechanical effect of balloon angioplasty. Case report with histology. American Journal of Roentgenology 1981;137: 867-71.

28 Athanasoulis CA. Percutaneous transluminal angioplasty: general principles. American Journal of Roentgenology 1980;135:893-900.

29 The EC/IC Bypass Study Group. Failure of extra-cranial/ intracranial arterial bypass to reduce the risk of ischaemic stroke. New Engl J Med 1985;313:1191-200.

30 Tievsky AL, Druy EM, Mardiat JG. Transluminal angioplasty in post-surgical stenosis of the extra-cranial cariotid artery. American Journal of Neuroradiology 1983;4:800-2

31 Courtheoux P, Theron J, Tournade A, Maiza D, Henriet JP, Braun JP. Percutaneous endoluminal angioplasty of postBraun JP. Percutaneous endoluminal angioplasty of postendarter.

32 The National Heart, Lung and Blood Institute Registry. Percutaneous transluminal coronary angioplasty in 198586 and 1977-81. New Engl J Med 1988;318:265-70. 